\title{
Autoimmune optic neuropathy: evaluation and
}

\section{treatment}

\author{
MARK J KUPERSMITH, ${ }^{*} \dagger$ RONALD M BURDE, $\S \|$ FLOYD A WARREN, $\dagger$ \\ TERRENCE G KLINGELE, $\S$ LARRY P FROHMAN, $\dagger$ HAL MITNICK
}

From the Departments of Neurology, ${ }^{*}$ and Ophthalmology, $\dagger$ and Medicine, $\ddagger$ New York University Medical Center and New York Eye and Ear Infirmary, New York, and Departments of Ophthalmology§ and Neurology and Neurological Surgery, || Washington University School of Medicine, St Louis, Missouri, USA

SUMMARY Fourteen patients, 12 of whom were women, with an age range from 26 to 56 years, presented with progressive or recurrent optic neuropathy, despite conventional doses of corticosteroid, and laboratory evidence of collagen vascular disease. The visual loss was severe and most had an acuity less than 20/200. Megadose corticosteroid therapy improved the vision in 11 of the 12 patients. Continued oral prednisone and cytotoxic drugs were necessary to maintain vision in nine patients. Patients with autoimmune optic neuropathy must be differentiated from cases with idiopathic optic neuritis or multiple sclerosis to facilitate the appropriate therapy.

Central nervous system dysfunction frequently occurs in patients with well-established collagen vascular disease (CVD) but is rarely the presenting feature in these diseases. 'Among such cases, optic neuropathy at presentation is even more rare $^{23}$ and it is not mentioned in most reviews of the topic. ${ }^{45}$ Cases of optic neuropathy are often described in association with myelopathy, the Devic's syndrome. ${ }^{267}$ The visual loss that most commonly occurs with CVD is in the retina, often secondary to vascular occlusion. ${ }^{8}$ However, sudden or progressive optic neuropathy has been described in patients with existing CVD, such as systemic lupus erythematosus ${ }^{9-12}$ and polyarteritis nodosa. ${ }^{1314}$ Both ischaemic and demyelinating lesions have been reported in the pathology of the optic nerves of these patients.

If the initial optic neuropathy occurs without obvious signs or complaints of systemic disease, it is often diagnosed as optic neuritis. If the second eye or spinal cord are subsequently involved, multiple sclerosis is then diagnosed. However, patients with optic neuropathy, associated with probable CVD, may be differentiated from those with multiple sclerosis because they often have a markedly positive antinuclear antibody (ANA). These cases, called

Address for reprint requests: Mark J Kupersmith, MD, 530 First Avenue, Suite 3B, New York, New York 10016, USA.

Received 5 January 1988 and in revised form 6 June 1988. Accepted 13 June 1988 "autoimmune" optic neuritis ${ }^{15}$ have laboratory evidence suggestive of a systemic vasculitis despite the frequent lack of systemic symptoms. It is important to distinguish these patients from those with primary demyelinating disease, because the former rarely recover spontaneously and are often left with severe visual loss despite conventional doses of corticosteroid. In contrast, the optic neuritis associated with multiple sclerosis commonly remits even without therapy. In patients with "autoimmune" optic neuritis, megadose corticosteroid, followed by lower doses of corticosteroid and immunosuppressive therapy, can promote recovery and prevent permanent visual loss. ${ }^{15}$

We report our experience with patients who appeared to have "autoimmune" optic neuritis. Visual loss was the initial complaints in all patients and none had overt clinical signs of CVD. Laboratory evaluation suggested a CVD and not multiple sclerosis as the aetiology in each case. Megadose corticosteroid or chemotherapy or both was necessary in many of these patients. A follow up period over 6 years in four patients, three of whom were previously reported, ${ }^{15}$ gives some perspective on this disease.

\section{Subjects and methods}

A retrospective review of the Neuro-ophthalmology service files at New York University Medical Center (1980 to 1987) and Washington University (1974 to 1987) revealed 14 
Table 1 Blood studies

\begin{tabular}{|c|c|c|c|c|c|c|c|c|c|c|}
\hline Case & C3 & $C 4$ & $E N A$ & $A D S D N A$ & $\begin{array}{l}\text { Anti- } \\
\text { RNP }\end{array}$ & $\begin{array}{l}\text { Anti- } \\
R N A\end{array}$ & $\boldsymbol{R F}$ & $E S R$ & $\begin{array}{l}\text { Anticardiolipin } \\
\text { antibodies }\end{array}$ & $A N A$ \\
\hline $\begin{array}{l}1 \\
2 \\
3 \\
4\end{array}$ & $\begin{array}{l}\mathbf{D} \\
\mathbf{N} \\
\mathbf{D} \\
\mathbf{N}\end{array}$ & $\begin{array}{l}\mathbf{D} \\
\mathbf{N} \\
\mathbf{N} \\
\mathbf{D}\end{array}$ & D & $\begin{array}{l}\mathbf{N} \\
\mathbf{D}\end{array}$ & D & & $\begin{array}{l}\mathbf{N} \\
\mathbf{N} \\
\mathbf{N} \\
\mathbf{N}\end{array}$ & $\begin{array}{l}3 \\
5 \text { to } 30 \\
12 \\
66\end{array}$ & & $\begin{array}{l}1+\text { homogenous speckled } \\
2+\text { homogenous nuclear } \\
1+\text { speckled } \\
2+\text { homogenous speckled } \\
\quad \text { nuclear } 1: 1028\end{array}$ \\
\hline $\begin{array}{r}5 \\
6 \\
7 \\
8 \\
9 \\
10 \\
11 \\
12 \\
13\end{array}$ & $\begin{array}{l}\mathbf{N} \\
\mathbf{N} \\
\mathbf{N} \\
\mathbf{D} \\
\mathbf{N} \\
\mathbf{N} \\
\mathbf{D} \\
\mathbf{N} \\
\mathbf{N}\end{array}$ & $\begin{array}{l}\mathbf{N} \\
\mathbf{N} \\
\mathbf{N} \\
\mathbf{D} \\
\mathbf{N} \\
\mathbf{N} \\
\mathbf{N} \\
\mathbf{N} \\
\mathbf{N}\end{array}$ & $\begin{array}{l}\mathbf{N} \\
\mathbf{N} \\
\mathbf{N} \\
\mathbf{N} \\
\mathbf{N}\end{array}$ & $\begin{array}{l}\mathbf{N} \\
\mathbf{N} \\
\mathbf{N} \\
\mathbf{N} \\
\mathbf{N} \\
\mathbf{N} \\
\mathbf{N} \\
\mathbf{N} \\
\mathbf{N}\end{array}$ & $\begin{array}{l}\mathbf{N} \\
\mathbf{N} \\
\mathbf{N} \\
\mathbf{N} \\
\mathbf{N} \\
\mathbf{N} \\
\mathbf{N}\end{array}$ & $\begin{array}{l}\mathbf{D} \\
\mathbf{N} \\
\mathbf{D} \\
\mathbf{N} \\
\mathbf{N} \\
\mathbf{N}\end{array}$ & $\begin{array}{l}\mathbf{N} \\
\mathbf{N} \\
\mathbf{N} \\
\mathbf{N} \\
\mathbf{N} \\
\mathbf{N} \\
\mathbf{N} \\
\mathbf{1}: 160 \\
\mathbf{N}\end{array}$ & $\begin{array}{r}35 \\
12 \\
11 \\
5 \\
17 \\
13 \\
15 \\
17 \\
12\end{array}$ & $\begin{array}{l}\text { IgM } \\
\mathbf{N} \\
\text { IgM } \\
\text { IgM } \\
\mathbf{N} \\
\text { IgM }\end{array}$ & $\begin{array}{l}1: 160 \text { speckled } \\
>1: 160 \text { diffuse } \\
1: 2560 \text { homogenous } \\
1: 320 \text { diffuse } \\
1: 80 \text { speckled } \\
\mathbf{N} \\
\mathbf{N} \\
1: 160 \text { speckled } \\
\mathbf{N}\end{array}$ \\
\hline 14 & $\mathbf{N}$ & $\mathbf{N}$ & $\mathbf{N}$ & $\mathbf{N}$ & $\mathbf{N}$ & & $1: 1280$ & 5 & & 1:160 speckled \\
\hline
\end{tabular}

$\mathbf{N}=$ normal or not detected.

$\mathrm{D}=$ decreased or detected.

$\mathbf{A}=$ abnormal.

patients who presented with optic neuropathy and laboratory data suggestive of a systemic CVD. The laboratory evaluation was not uniformly performed because as our understanding of this illness evolved, we began to intensify our search for more cases and laboratory abnormalities. Early on, anti-nuclear antibody (ANA), Rheumatoid Factor (RF), complement levels (C3, C4), LE preparation, sedimentation rate (ESR), and antidoublestranded DNA (ADSDNA) were performed. Later cases had a broader blood screen (table 1). Normal sun-exposed skin was biopsied and investigated for immune complex deposition and complement using direct immunofluorescent staining ${ }^{16}$ in seven of the last eight cases. Computed tomography (CT) or magnetic resonances image (MRI) or both were performed in all cases. The spinal fluid was analysed for cell content, protein, glucose, VDRL, and gamma globulin or oligoclonal bands in 13 cases.

\section{Results}

\section{Clinical presentation}

Twelve women and two men (cases 7 and 10) with a mean age of $40 \cdot 1$ (range 26 to 56 years) were included in the study (table 2). Prior to our treatment with large doses of corticosteroids or immunosuppressives, symptoms or findings of systemic or neurological dysfunction occurred in seven patients. Case 1 had a uveitis and pars planitis. Case 4 had numbness of the right face and hand with a previous optic neuropathy and anterior uveitis. Case 5 had vague arthralgias, Raynaud's phenomenon but an otherwise normal examination. Case 6 had laboratory evidence of hypothyroidism and complaints of foot discomfort. Case 9 had a history that suggested the presence of osteoarthritis but had a normal examination. She had been treated with radioactive iodine for hyperthyroidism. Case 12 had a previous optic neuropathy and a spontaneous complaint of Lhermitte's sign. Case 14 had a history of a low back pain and eczematoid rash with a normal examination. A previous bout of optic neuropathy resolved without therapy.

Both eyes were involved in nine patients. Four patients had a unilateral optic neuropathy, 1 to 17 years prior to involvement of the second eye. Prior to our evaluation, six patients were diagnosed as having multiple sclerosis because both optic nerves were involved by the disease.

Visual loss was progressive, often painless, and deteriorated over 1 week (two cases) to 6 months (a mean of 1.98 months) prior to our evaluation in 20 eyes. Nine patients were first treated by other physicians without visual recovery. One case (No 14) had an episode in the other eye that spontaneously improved. Eight patients were treated with oral prednisone from 60 to $100 \mathrm{mg}$ daily. Case 13 had received one week of intravenous ACTH 80 units daily. Snellen acuity in the 20 newly affected eyes ranged from 20/40 to no light perception; 13 eyes had vision poorer than 20/200 (table 2). The fundus showed an atrophic disc in the four eyes with prior longstanding visual loss. Referring physicians reported initially normal fundi in 16 eyes and optic disc swelling in four eyes (two patients). We observed optic disc pallor in all of these 20 eyes. The neurological examination was normal, except for the eyes, in all patients. No patient had clinical signs suggestive of systemic collagen vascular disease.

\section{Laboratory evaluation (table 1)}

The ANA was the most consistently abnormal blood study since the first nine patients were included in the study on the basis of this abnormality (table 1 ). The first three patients had positive ANAs prior to dilution testing; eight of the remaining cases had ANAs 1:80 or 
greater. No consistent pattern of staining was seen in these patients.

Other blood abnormalities (table 1) suggestive of CVD were inconsistently found. The Raji was positive in one of three cases. No abnormalities were present in Anti-Smith (six cases), LE preparations (11 cases), or immune electrophoresis (10 cases) studies. Only the anticardiolipin antigen antibody was demonstrated with any regularity (four of the five patients evaluated).

The spinal fluid was abnormal in four of the 13 patients who had a lumbar puncture. Oligoclonal band analysis was performed in all patients except Case 3 (this case had a negative myelin basic protein). Case 5 had a protein of $67 \mathrm{mg} \%$. Case 8 had 39 lymphocytes/ml. Cases 1 and 4 had oligoclonal bands. Case 4 also had a gamma globulin of $32 \%$. Cases 4 and 8 had normal spinal fluid analysis 1 year and 9 months respectively, after beginning therapy (see below).

Contrast enhanced CT was normal in 13/14 patients. MRI was normal in 3/5 cases. Case 8 had a swollen chiasm seen on a previous CT scan. Case 14 had central white matter and peri-ventricular signal increase. Repeat MRI in cases 7 and 8 were normal following therapy (see below).

Skin biopsies were abnormal in six of seven cases. The haematoxylin and eosin examination was abnormal only in case 14 , who had a leukoclastic vasculitis but no immune complex deposition. Immunofluorescent staining showed IgG deposits at the dermalepidermal junction and around the blood vessels in the epidermis of cases 10 and 11 . Homogeneous deposits of $\mathrm{IgG}$ and fibrin were also found about papillary blood vessels in the epidermis of case 10 . Case 13 had linear $\mathrm{IgG}, \mathrm{C}_{3}$ and $\mathrm{IgA}$ at the epidermal-dermal junction. IgM, in granular deposits was found at the epidermal-dermal junction of case 7 and in the collagen of the dermis of case 8 .

Treatment course (table 2)

Intravenous methylprednisolone $(1000 \mathrm{mg}$ to $2000 \mathrm{mg} /$ daily) was given, in divided doses for five to seven days, to 10 patients. The dose was tapered once visual recovery began or withdrawn if no recovery occurred (Case 13). An eleventh patient (Case 5) refused intravenous therapy but improved on $400 \mathrm{mg}$

Table 2 Clinical presentation and treatment

\begin{tabular}{|c|c|c|c|c|c|c|c|c|}
\hline Case & $\begin{array}{l}\text { Age } \\
(y r)\end{array}$ & $\begin{array}{l}\text { Failure } \\
\text { prednisone } \\
m g\end{array}$ & $\begin{array}{l}\text { Starting } \\
\text { acuity } \\
O D / O S\end{array}$ & $\begin{array}{l}\text { Maximum } \\
\text { acuity } \\
O D / O S\end{array}$ & $\begin{array}{l}\text { Pulse } \\
\text { steroid } \\
\text { mg (5-7 } \\
\text { days) }\end{array}$ & $\begin{array}{l}\text { Months of } \\
\text { prednisone } \\
\text { prior to } \\
\text { chemo }\end{array}$ & $\begin{array}{l}\text { Chemo- } \\
\text { therapy mg } \\
\text { Prednisone } \\
\text { mg }\end{array}$ & $\begin{array}{l}\text { Follow-up } \\
\text { time } \\
\text { years }\end{array}$ \\
\hline 1 & 44 & 100 & $\begin{array}{l}\text { LP } \\
20 / 20\end{array}$ & $\begin{array}{l}20 / 25 \\
20 / 20\end{array}$ & $\begin{array}{l}1000 \\
2000\end{array}$ & 12 & $\begin{array}{l}\text { CLB } 6 \\
\text { Prednisone }\end{array}$ & $6 \cdot 5$ \\
\hline 2 & 42 & 100 & NLPł & $\begin{array}{l}\text { NLP } \\
20 / 20\end{array}$ & $\begin{array}{l}1000, \text { ACTH } \\
2000^{*}\end{array}$ & 4 & $\begin{array}{l}\text { CLB } 6 \\
\text { Prednisone }\end{array}$ & $6 \cdot 5$ \\
\hline 3 & 26 & 100 & HM & $\begin{array}{l}20 / 25 \\
20 / 25\end{array}$ & 60 to 80 & 3 & $\begin{array}{l}\text { CPM } 150 \\
\text { AZA } 100\end{array}$ & $5 \cdot 5$ \\
\hline 4 & 26 & 100 & $\begin{array}{l}\mathrm{CF} \\
20 / 300 t\end{array}$ & $\begin{array}{l}20 / 25 \\
20 / 300\end{array}$ & 2000 & $1 \cdot 5$ & $\begin{array}{l}\text { CLB } 6 \\
\text { AZA } 75\end{array}$ & $6 \cdot 5$ \\
\hline 5 & 56 & & $\begin{array}{l}20 / 400 \\
20 / 20\end{array}$ & $\begin{array}{l}20 / 30 \\
20 / 20\end{array}$ & 200 & 1 & $\begin{array}{l}\text { AZA } 125 \\
\text { Prednisone } 30\end{array}$ & 0.5 \\
\hline 6 & 47 & 20 & $\begin{array}{l}20 / 20 \\
10 / 400\end{array}$ & $20 / 20$ & 1000 & 1 & $\begin{array}{l}\text { AZA } 50 \\
\text { Prednisone } 60\end{array}$ & 0 \\
\hline 7 & 45 & 60 & $\begin{array}{l}\text { LP } \\
\text { NLP }\end{array}$ & $\begin{array}{l}20 / 50 \\
\text { LP }\end{array}$ & $\begin{array}{l}1000 \\
1000^{*}\end{array}$ & 1 & $\begin{array}{l}\text { CLB } 8 \text { Prednisone } \\
\text { AZA 200† } \\
\text { Prednisone 100* } \\
\text { CLB 6 } \\
\text { Prednisone 5t }\end{array}$ & $5 \cdot 5$ \\
\hline 8 & 27 & 80 & $\begin{array}{l}20 / 60 \\
\text { NLP }\end{array}$ & $\begin{array}{l}20 / 20 \\
\mathrm{CF}\end{array}$ & $\begin{array}{l}1000 \\
1000^{*}\end{array}$ & 1 & $\begin{array}{l}\text { CLB 6, } \\
\text { Prednisone } 10 \\
\text { AZA 200† } \\
\text { Prednisone 10† }\end{array}$ & 0.5 \\
\hline 9 & 43 & & $\begin{array}{l}20 / 400 \\
20 / 20\end{array}$ & $\begin{array}{l}20 / 25 \\
20 / 20\end{array}$ & 1000 & 3 & & 6.5 \\
\hline 10 & 44 & & $\begin{array}{l}20 / 40 \\
20 / 70\end{array}$ & $\begin{array}{l}20 / 30 \\
20 / 70\end{array}$ & 1000 & 1 & & 0.5 \\
\hline 11 & 30 & & $\begin{array}{l}20 / 70 \\
20 / 70\end{array}$ & $\begin{array}{l}20 / 70 \\
20 / 70\end{array}$ & & & & 1.0 \\
\hline 12 & 40 & 120 & $\mathrm{CF}_{\mathbf{\gamma}}$ & $\begin{array}{l}20 / 25 \\
\text { NLP }\end{array}$ & 1000 & 3 & & 0.5 \\
\hline 13 & 45 & $\begin{array}{l}\text { ACTH } \\
80 \text { units }\end{array}$ & $\begin{array}{l}2 / 400 t \\
2 / 400\end{array}$ & $\begin{array}{l}2 / 400 \\
2 / 400\end{array}$ & 1000 & 0 & & $2 \cdot 0$ \\
\hline 14 & 47 & & $\begin{array}{l}20 / 20+ \\
20 / 100\end{array}$ & $\begin{array}{l}20 / 20 \\
20 / 30\end{array}$ & 80 & 1 & & 0.4 \\
\hline
\end{tabular}

* = repulse with recurrence.

$t=$ recurred after off medications.

$\ddagger=$ old lesion. 
of oral prednisone daily. The dose of corticosteroid was gradually reduced as vision improved. Two other patients (Cases 3 and 14) were treated with 80 to $100 \mathrm{mg}$ of oral prednisone daily. Case 14, who experienced spontaneous improvement in vision of the right eye 9 months prior to this episode, required the shortest treatment period (1 month). Prior to immunosuppressive therapy, worsening of visual acuity developed as the prednisone was lowered or withdrawn (over 1-3 months) in eight patients. This prompted either a repetition of the intravenous methylprednisolone therapy or an increase in the oral prednisone dose in the eight patients.

Corticosteroid intolerance or visual failure, 1 to 12 months after pulse megadose oral or intravenous corticosteroids, necessitated immunosuppressive therapy in 10 patients. Chlorambucil (CBL) was the first agent added in cases $1,2,4,7$, and 8 . The white blood cell count was kept below $4000 \mathrm{~mm}^{3}$ with $6 \mathrm{mg}$ of chlorambucil daily. The vision improved and the prednisone dose was lowered in these five cases. Case 4 experienced fluctuating vision 3 months after complete withdrawal from prednisone, and azathioprine (AZA), $75 \mathrm{mg}$ daily, stabilised her vision. Case 3 was treated with cyclophosphamide (CPM), $150 \mathrm{mg}$ daily, but in 2 months when the prednisone was lowered to $20 \mathrm{mg}$, the vision diminished. The vision returned when the prednisone was increased to $100 \mathrm{mg}$ daily and azathioprine, $100 \mathrm{mg}$ daily, was added. The prednisone was gradually reduced over 6 months without an additional flare-up. Cases 5 and 6 were given azathioprine in addition to corticosteroids. Case 5 required no other immunosuppressive agents, and Case 6 refused further treatment after one week of azathioprine.

Immunosuppressive agents alone or in combination with prednisone were given for six months to one year in nine patients. Cases 7 and 8 experienced a recurrence of visual loss, when the drugs were stopped after one year and six months of treatment, respectively. The vision decreased in both eyes of both patients and myelopathy developed in Case 7. MRI of the head or spinal cord, or spinal fluid analysis revealed no evidence of multiple sclerosis. Both patients were given intravenous methylprednisolone, $1000 \mathrm{mg}$ daily, for five days. The dose of corticosteroid was lowered, $100 \mathrm{mg}$ of azathioprine per day were prescribed. The azathioprine was increased to $200 \mathrm{mg}$ daily in both patients. Despite a white blood cell count at/or below 4000 cells $/ \mathrm{mm}^{3}$, the myelopathy and vision of Case 7 became progressively worse. The azathioprine was discontinued, and $6 \mathrm{mg}$ chlorambucil per day was begun. The patient's vision improved, and his myelopathy resolved. Both patients are currently on daily azathioprine or chlorambucil as well as alternate-day prednisone $(10 \mathrm{mg})$ with stable neurological and ophthalmological examinations for 12 months.

Five of these patients (cases 9, 10, 11, 12 and 14) were successfully treated with a 1-3 month trial of oral prednisone. They did not require immunosuppressive drugs. Case 11 experienced several exacerbations whenever her prednisone was withdrawn, prior to our evaluation. She has been maintained, without a recurrence, on piroxicam for the 12 months under our observation.

After large doses of corticosteroids or immunosuppressive therapy, or both, four patients (two without prior signs of neurologic dysfunction) developed signs or symptoms of systemic disease or of the neuraxis. Case 2 developed polymyositis. Case 7 had a myelopathy, and Case 4 had a transient right hemiparesis. Case 12 developed scleroderma.

Complications occurred as a result of or concomitant with therapy in six patients. Case 2 developed a cataract, requiring cataract extraction that was performed without complication. Case 3 had pneumocystis carinii pneumonia that responded to antibiotics and withdrawal from prednisone. Case 4 had herpetic keratitis that responded to local ophthalmic drop and ointment therapy. Case 4 also experienced depression and cushingoid features which responded to withdrawal from prednisone. Case 7 had osteoporosis of the knee joint and lumbar spine that remained stable on lower doses of prednisone. Case 8 developed sepsis while on chlorambucil when she developed agranulocytosis; she failed to keep appointments and therefore to have her blood count checked for over one month. She responded to antibiotic therapy and withdrawal of the chlorambucil.

Visual benefit was maintained following withdrawal of all medications in five of the seven patients treated with immunosuppressive agents and corticosteroids, in the four patients treated with corticosteroids alone, and in the one patient treated with corticosteroids followed by piroxicam. Cases 1, 2, 4, and 9 have been followed for over 6.5 years. Case 5 was seen for six months, during which time she did not experience a recurrence, but subsequently was lost to follow up. Case 10, 12, and 14 have been followed for less than one year. No new neurological signs or symptoms have developed in these patients. As previously outlined, Cases 7 and 8 had a recurrence of visual loss following immunosuppressive therapy but recovered vision in their better eyes with reinstitution of therapy.

Significant recovery and maintenance of usable, functional vision occurred in 11 patients. A twelfth patient (Case 11) has maintained a stable bilateral acuity of 20/70. Nine of the patients had a final acuity of $20 / 25$ or better in at least one eye. Three patients had acuity between $20 / 50$ and $20 / 70$ in at least one eye. Case 6, who refused therapy, has maintained vision in one eye at $20 / 20$ but the affected eye is less than $20 / 400$. 
Case 13 has visual acuity of approximately $2 / 400$ in each eye.

\section{Discussion}

Unilateral or bilateral optic neuropathy can occur as the initial manifestation of a systemic CVD. This optic neuropathy is marked by steroid-responsiveness and steroid-dependence. It can recur or progress over weeks and months. Slowly progressive optic neuritis can occur in patients with longstanding multiple sclerosis, but is rarely the initial symptom. ${ }^{17}$ Spontaneous remission, often seen with idiopathic optic neuritis or with optic neuritis as part of multiple sclerosis, was found in only one of our patients. The visual loss is often severe; prior to therapy the acuity was less than 20/200 in 17 eyes of 11 of our patients. Prednisone, in doses from $100 \mathrm{mg}$ to $200 \mathrm{mg}$ daily, may not restore vision.

The laboratory evaluation suggested a CVD as the probable cause of the optic neuropathy in order to be included in this series. Since this was not a prospective study, and more extensive testing was performed on patients seen later, the laboratory evaluations were not uniform. Eleven patients had a positive ANA with a variable, non-diagnostic pattern. The ANA is not specific in that a wide range of antibodies to several components of the nucleus ${ }^{18}$ can cause a positive test. A positive ANA occurs in many different connective tissue disorders. Some patients with multiple sclerosis can have a mildly positive ANA, but detection of the ANA in these patients requires a technique sensitive enough to measure their low titres. Diffuse-speckled or nucleolar-speckled patterns have been observed in multiple sclerosis patients. ${ }^{1920}$ Other peripheral blood markers of systemic autoimmune disease have also been described in cases of multiple sclerosis; circulating immune complexes, ${ }^{21}{ }^{22} \mathrm{C}$-reactive protein, $\mathrm{C}_{3}$ proactivator, and IgM elevation ${ }^{23}$ have all been demonstrated. IgG deposits have even been found in the kidney of a single patient with multiple sclerosis. ${ }^{24}$ Thus, the presence of immune complexes in the blood or a weakly positive ANA does not absolutely exclude multiple sclerosis or include CVD as the aetiology of the optic neuropathy in our patients. On the other hand, the finding of such markers of autoimmune disease should suggest at least that an autoimmune vasculitis may be masquerading as multiple sclerosis.

Most of our patients had significant elevation of the ANA and other tests suggestive of CVD. In addition to the positive ANA, decreased $\mathrm{C} 3$ or $\mathrm{C} 4$ complement levels (36\% of the patients) and anticardiolipin antibodies ( $80 \%$ of the tested patients) were strongly suggestive of CVD. Immune complex or complement deposition in the skin biopsy ( $75 \%$ of our biopsies) of normal skin is reported in $80 \%$ of patients with systemic lupus erythematosus and mixed connective tissue disorders ${ }^{16}$ but not with multiple sclerosis. Spinal fluid cellular response, elevated protein, elevated IgG, or oligoclonal banding, all indicative only of the inflammatory nature of the disease, occurred in $31 \%$ of our patients. Additionally, only one of our cases had CT or MRI lesions of white matter, typically found in patients with multiple sclerosis. Similar white matter lesions have been recently described in patients with systemic lupus erythematosus. ${ }^{25}$

Only three of our patients had symptoms or findings suggestive of central nervous system lesions outside the optic pathway. One patient developed his findings 6 months after being withdrawn from prednisone and chlorambucil. He had a bilateral optic neuropathy and myelopathy, consistent with Devic's syndrome. He had two normal MRIs and two normal lumbar punctures and an ANA 1:2560, leaving little doubt that he had a CVD. Another patient with facial numbness at the onset, developed a right hemiparesis after withdrawal from corticosteroid. She had an erythrocyte sedimentation rate of $66 \mathrm{~mm}$ in one hour, an ANA 1:1280, positive Raji cell immune complex and ENA, and low serum complement, all diagnostic of CVD. The third patient (Case 12) with Lhermitte's sign had a negative neurological examination, normal spinal fluid, and a negative skin biopsy. The patient refused CT and MRI. The only blood abnormalities were an ANA 1:160 and a latex fixation 1:160. The diagnosis was not certain in this case until she developed CREST syndrome (calcinosis, Raynaud's oesophageal motility disorder, sclerodactyly) 6 months after her withdrawal from corticosteroids.

Megadose intravenous corticosteroid therapy dramatically improved the vision in 11 patients, nine of whom previously failed to benefit from conventional large doses of oral prednisone. The response to corticosteroids suggested oedema and inflammation rather than ischaemia as the mechanisms of optic neuropathy, but additional immunosuppressive effects with megadose corticosteroids may have been significant ${ }^{26} \mathrm{~A}$ twelfth patient had minimal acuity or visual field benefit, but the vision had deteriorated slowly over one year before treatment. One patient derived no benefit from the intravenous corticosteroids. No eyes with severe visual loss of more than one year improved when treatment was administered for involvement of the second eye.

As the corticosteroids were reduced to avoid complications, immunosuppressive therapy was often required to maintain recovered visual acuity. Vision eteriorated with a single chemotherapeutic agent in three cases. Switching agents in one patient or adding a second agent, with different effects on the immune system in the other two patients, improved and 
stabilised the vision. The addition of chemotherapy allowed lower doses of corticosteroids to be used with fewer complications. We are fully aware of the potential side effects of the immunosuppressive agents used, especially the potential for the development of secondary neoplasms. Recently published papers deal with the acute side effects of one of these agents in the treatment of multiple sclerosis ${ }^{27}$ and with its long-term oncologic effect. ${ }^{28}$ In light of this, chlorambucil or azathioprine would appear to be safer drugs. Haemograms are used to ensure that an adequate dose is given to achieve immunosuppression without severe susceptibility to infection.

Immunosuppressive therapy may be beneficial in cases with multiple sclerosis ${ }^{29} 30$ and often improves or stabilises the deficits caused by various rheumatological diseases. ${ }^{31}$ However, not all patients with multiple sclerosis or $\mathrm{CVD}^{32}$ related optic neuropathy maintain or improve vision (our case 13) even with this therapy.

The laboratory evidence and the clinincal course in our patients supports a CVD aetiology rather than primary demyelinating disease as the cause for the optic neuropathy. Patients with progressive optic neuropathy or optic neuritis with severe visual loss that does not recover should be investigated for systemic vasculitis. The full extent of the evaluation necessary to include a CVD or exclude multiple sclerosis remains to be determined. A strongly positive ANA, anti-cardiolipin antigen antibody, antiDSDNA, or anti-RNA, serological studies, immune complex deposition in normal skin, and no white matter plaques on MRI are strongly suggestive of collagen vascular disease. Once diagnosed, patients with autoimmune optic neuritis may require megadose corticosteroid therapy followed by a slowly tapering withdrawal. Immunosuppressive agents should be added if visual loss recurs at a tolerable dose of corticosteroids or if steroids alone do not prevent recurrence of visual loss.

This work was presented in part at the American Academy of Neurology, April 27-May 3, 1986, New Orleans, Louisiana. Supported by Research to Prevent Blindness, Inc and the Surgery Fund of the Kirby Laboratory Fund.

\section{References}

1 Siekert RG, Clark EC. Neurologic signs and symptoms as early manifestations of systemic lupus erythematosus. Neurology 1955;5:84-8.

2 Hackett ER, Martinez RD, Larson PF, et al. Optic neuritis in systemic lupus erythematosus. Arch Neurol 1974;31:9-11.

3 Rush JA, Kennberdell JS, Martinez AJ. Primary idiopathic inflammation of the optic nerve. Am J Ophthalmol 1982;93: 312-6.

4 Fulford KWM, Catterall RD, Delhanty JJ, et al. A collagen disorder of the nervous system presenting as multiple sclerosis. Brain 1972;95:373-86.

5 Johnson RT, Richardson EP. The neurological manifestations of systemic lupus erythematosus Medicine (Baltimore) 1968; 47:337-69.

6 April RA, Vansonnenberg E. A case of meuromyelitis optica (Devic's syndrome) in systemic lupus erythematosus. Clin- icopathologic report and review of the literature. Neurology 1976;26:1066-70.

7 Kinney EL, Berdoff RL, Rao Ns, et al. Devic's syndrome and systemic lupus erythematosus: a case report with necropsy. Arch Neurol 1979;36:643-4.

8 Gold DH, Morris DA, Henkind P. Ocular findings in systemic lupus erythematosus. Br J Ophthalmol 1972;56:800-4.

9 Hollenhorst RW, Henderson JW. The ocular manifestations of the diffuse collagen diseases. Am J Med Sci 1951;221:211-22.

10 Estes D, Christian CL. The natural history of systemic lupus erythematosus by prospective analysis. Medicine (Baltimore) 1971;50:85-95.

11 Jabs DA, Miller NR, Newman SA, et al. Optic neuropathy in systemic lupus erythematosus. Arch Ophthalmol 1986;104: 564-8.

12 Lessell S. The neuro-ophthalmology of systemic lupus erythematosus. Doc Ophthalmol 1979;47:13-42.

13 Goldstein I, Wexler D. Bilateral atrophy of the optic nerve in periarteritis nodosa: a microscopic study. Arch Ophthalmol 1937;18:767-73.

14 Kimbrell OC, Wheliss JA. Polyarteritis nodosa complicated by bilateral optic neuropathy. JAMA 1967;201:61-2.

15 Dutton JJ, Burde RM, Klingele TG. Autoimmune retrobulbar optic neuritis. Am J Ophthalmol 1982;94:11-17.

16 Jablonksa S, Chorzelski TP. Lupus erythematosus. In: Fry L, Seah PP, eds. Immunological Aspects of Skin Diseases. New York: John Wiley and Sons, 1974:66.

17 Ormerod IEC, MacDonald WI. Multiple sclerosis presenting with progressive visual failure. J Neurol Neurosurg Psychiatry 1984; 47:943-6.

18 Antinuclear antibodies. Editorial. Lancet 1984;ii:611-3.

19 Dore-Duffy P, Donaldson JO, Rothman BL, et al. Antinuclear antibodies in multiple sclerosis. Arch Neurol 1982;39:504-6.

20 Nordal HJ, Vandvik B. Evidence of local synthesis of smoothmuscle antibodies in the central nervous system in isolated cases of multiple sclerosis and chronic lymphocytic meningoencephalitis. Scand J Immunol 1977;6:327-34.

21 Tachovsky TG, Lisak RP, Koprowski H, et al. Circulating immune complexes in multiple sclerosis and other neurological diseases. Lancet 1976;11:997-9.

22 Dasgupta MK, Warren KG, Johny KV, Dossetor JB. Circulating immune complexes in multiple sclerosis: relation with disease activity. Neurology 1982;32:1000-4.

23 Dowling PC, Cook SD. Disease markers in acute multiple sclerosis. Arch Neurol 1976;33:668-70.

24 Whitaker JN, Dowling PC, Cook SD. Immunofluorescent studies of the kidney in human neurologic disorders. J Neuropath Exp Neurol 1971;30:129-30.

25 Miller DH, Ormerod IEC, Gibson A, duBoulay EPGH, Rudge P, MacDonald WI. MR brain scanning in patients with vasculitis: differentiation from multiple sclerosis. Neuroradiology 1987; 29:226-31.

26 Fauci AS, Dale DC, Balow JE. Glucocorticosteroid therapy: mechanisms of action and clinical considerations. Ann Int Med 1976;84:304-15.

27 Myers LW, Fahey JL, Moody DJ, et al. Cyclophosphamide 'Pulses' in chronic progressive multiple sclerosis. A preliminary clinical trial. Arch Neurol 1987; 44:828-32.

28 Baker GL, Kahl LE, Zee BC, Stolzer BL, et al. Malignancy following treatment of rheumatoid arthritis with cyclophosphamide. Long-term case-control follow-up study. Am J Med 1987;83:1-16.

29 Hauser SL, Dawson DM, Lehrich JR, et al. Intensive immunosuppression in progressive multiple sclerosis. A randomized, threearm study of high-dose intravenous cyclophosphamide, plasma exchange, and ACTH. N Engl J Med 1983;308:173-80.

30 Mertin J, Knight S, Rudge P, et al. Double-blind, controlled trial of immunosuppression in treatment of multiple sclerosis. Lancet 1980;ii:949-51.

31 Austin HA, Klipper JH, Balow JE, et al. Therapy of lupus nephritis. Controlled trial of prednisone and cytotoxic drugs. $N$ Engl J Med 1986;314:614-9.

32 Gressel MG, Tomsak RL. Recurrent bilateral optic neuropathy in mixed connective tissue disease. J Clin Neuro-ophthalmol 1983;3:101-4. 
A Colour Atlas of Clinical Neurology. By Malcolm Parsons. (Pp 216; \$19.50.) London: Wolfe Medical, 1988.

This work contains 603 pictures with five tables; 230 of the figures are photographs, usually in colour, of clinical signs and include 39 pathological or operative specimens. The contents include a mixture of pathology, such as cerebral tumours, vascular diseases, infections, developmental disorders, and symptoms, for example, blackouts, and paraplegia. There are also sections on cranial nerves, higher functions of the brain and peripheral lesions. These have some features about examination. Short sections are provided with explanatory text emphasising common occurrences and also pointing out various pitfalls with examples of misdiagnosis. Obviously with a pictorial text some signs are much more easily portrayed and others, like movement disorders, fare less well.

The author's aim is to expand the neurological signs which patients may show and try to indicate the path that should be logically followed in their investigation. To that end there are 263 pictures of radiological investigations. These include many plain radiographs, isotope and computed tomographic brain scans with some films of myelograms, angiograms, ventriculograms and even air studies. It is disappointing that there are no pictures of magnetic resonance imaging but the text was first published in 1983. Traces from eight electro-encephalograms, three electrocardiograms, two electromyograms and one visual evoked potential are included as well as two tables of cerebrospinal fluid findings and one picture of cerebrospinal fluid to indicate the use of these important investigations.

Over 100 line drawings, some showing simplified anatomical pathways, and others of useful myotome and dermatome innervation, or reflex levels, supplement the text. These are of great help to the reader emphasising the important role of a basic understanding of clinical anatomy in neurological practice. The succinct comments in the text stress the author's views on what is important in causation, diagnosis and management. The reader will follow this advice with benefit.

This work is a useful adjunct which may support the student or junior doctor's neurological textbooks but will need to be supplemented by further reading. For the number of pictures it is reasonably priced.

Dr Parsons has also published Diagnostic Picture Tests in Clinical Neurology and is to be complimented on his promotion of pic- torial aids to neurological teaching.

T FOWLER

Treatment of Glioma. Edited by J Suzuki. (Pp 225; DM 148.00.) Berlin: Springer, 1988.

This is a collection of chapters by 16 writers from the Tohoka University School of Medicine, Sendai, the Akita University Hospital and the Medical College of Ohita, Japan. The title is misleading because the book contains a study of the epidemiology of gliomas, the effects of different treatment modalities on glioma cell cultures and animal brain tumour models, as well as their analysis of treatment of human gliomas.

The epidemiological study is well presented in the form of tables and a clear text. It is based on 662 glioma cases presenting in the Tohoku district between 1980 and 1984, but only $70 \%$ of these cases were verified neuropathologically using the WHO classification. The next chapter is a literature review on the therapeutic results in glioblastoma which is referenced up to 1983 and concludes that the results are disappointing This chapter seems unnecessary since the information and conclusions will probably be known to most workers likely to be interested in reading this book.

The next section gives a detailed account of the experimental method and results of the effects of radiation and cytotoxic drugs on monolayer and spheroid cell culture of gliomas and a brain tumour model. The experimental designs try to simulate the biological consequences of tumour cells receiving poor nutrition and oxygen supply by using different sized glioma spheroids and a hypoxic tumour preparation. Whilst the results are as one would expect from the general oncological literature, the experimental designs are elegant and the implications for the treatment of human brain tumours is discussed. Most of these results have been published in the Japanese literature, so the data may be new to Englishspeaking workers. It is a section that the clinician may wish to browse through before turning to the final section on clinical studies.

The authors preface this section by declaring that their experimental studies formed the basis of their clinical studies, which is a laudable principle, but in practice we all know it turns out differently. The authors describe RAFP therapy for their patients. This means a combination of external beam radiotherapy, ACNU (a nitrosurea) as a radio sensitiser and cytotoxic drug which is claimed to be enhanced by masked $5 F U$ called FT-207 and finally PSK, a polysaccharide, which is claimed strengthens the immunological mechanisms responsible for killing brain tumour cells.

Each chapter in the clinical section is dedicated to a rudimentary statistical analysis of a specific glioma type together with a review of the literature. Most patients receive surgery but less than $50 \%$ of any specific glioma group receive RAFP compared with a single adjuvant therapy. RAFP is shown to produce significant benefit in cases of anaplastic astrocytoma and medulloblastoma compared with single modality adjuvant treatment. Whether radiotherapy is beneficial for patients with oligodendrogliomas is controversial; whilst accepting this point, the authors fail to address their analysis to this problem. However, a final chapter on measuring the effect of RAFP therapy by MR imaging is interesting but not conclusive. The book will be of interest to the specialist neurosurgeon mainly for ideas on design of experiment and clinical protocols, and to the general neurosurgeon for the literature reviews in the clinical section, rather than the actual clinical results themselves, which are well documented elsewhere.

JOHN WILDEN

\section{Notices}

World Federations of Societies of Biological Psychiatry. Regional Psychiatric Symposium. This will be held 10-11 October 1989 in Budapest, Hungary. Details may be obtained from: Congress Bureaux Motesz, Budapest, POB 32, H-1361, Hungary.

The First International Congress of Movement Disorders. Sponsored jointly by the International Medical Society of Motor Disturbances and the Movement Disorders Society, this will be held 25-27 April, 1990 in Washington DC, USA. Information may be obtained from Mark Hallett, MD, NINDS, NIH Building 10, Room 5N226, Bethesda, Maryland 20892, USA.

\section{Correction}

Autoimmune optic neuropathy: evaluation and treatment. Kupersmith MJ, et al, J Neurol Neurosurg Psychiatry 1988;51: $1381-6$.

In Table 1 , the heading of column 7 should be Anti-RANA, not Anti-RNA. 